\title{
Editorial
}

\section{Seeing the Panorama of Social Work}

\author{
James G. Daley
}

A

s Editor of Advances, I am offered a rare gift. I see a wide range of manuscripts that seek to expound on some aspect of Social Work. Some make the cut and become articles in Advances, while others are rejected because they need more work. All of the submissions are Social Work at its finest. All the manuscripts stimulate my thinking about how Social Work as a profession advances and towards what future. This issue is an excellent illustration of that stimulation.

This edition is a potpourri of interesting issues that affect social workers. Besel and colleagues insightful article describes how agencies and courts can effectively partner to foster program sustainability. Danis' article emphasizes the key factors that influence a social worker's effectiveness with battered women. Collins and Moore's article highlights an often forgotten but vital issue: the preference of African Americans to be addressed by their last name. Wilks and Spivey discuss how journal editors value reference list accuracy. Hodge illustrates theoretical ideas that underlie the spiritual assessment conducted by social workers. Sherr and Wolfer suggest ways that faithbased organizations can be incorporated into social work curriculum. Miller analyzes whether prisoners with mental retardation were able to adequately participatein their legal process. Half of the articles are empirical studies, while the other half are practice-focused. All of the articles address topics important to consider.

As I was piecing together this issue, I pondered past issues of Advances and the topics covered. Of course, the Spring 2004 issue focused on detailed descriptions of student assessment and various ways we strive to educate future social workers. The Spring 2003 issue included topics such as biophilia (person and environment link), hearing children of violence, and multi-cultural practice. Fall 2003 highlighted such issues as on-line practice guidelines, issues of rural and urban practices, risk and liability, and poetry therapy techniques. Spring 2002 issue covered managed care, kinship care, and research with African Americans. Within two short years, Advances has covered quite a range of topics. The Spring 2005 issue is being formed now, with leaders in thefield contributing a diversecollection of views about the future of Social Work as a profession.

So what is my point? The high quality of scholarship captures the panorama that is Social Work. The profession is not just clinical precision or academic rigor. Though we have depth of expertise in our chosen practice setting, we must be constantly open to widening our lens of knowledge beyond our parochial setting. A social worker who works with cancer patients is pushed to consider issues such as using a person's first name when working with African Americans, or how to effectively conduct a spiritual assessment, or strategies to foster program sustainability, or how to use bibliotherapy with patients, or consider biophilic principles to enhance well being. 
Regardless of the setting, a social worker reading Advances should feel challenged to think differently, to consider an issue not on our radar screen, to gain additional tips for practice. That is my goal. I striveto help expand the reader's perspective. In the special issues, the reader gets depth of a topic. In the regular issues, the reader gets a diverse collection.

We have been fortunate to have a wide range of manuscripts submitted for consideration. Each manuscript is critiqued by reviewers. As Editor, I take those accepted manuscripts and strive to build a diverse, stimulating issue. Whether administrator, clinician, or researcher, Advances offers useful articles.

So, to the reader, I offer this suggestion. Read each article and consider how it can make you a better social worker. This issue has lots to offer. Enjoy! 